\title{
BMJ Open Knowledge, attitude and self-efficacy of elderly caregivers in Chinese nursing homes: a cross-sectional study in Liaoning Province
}

\author{
Huijun Zhang, ${ }^{1,2} \mathrm{He}^{\mathrm{S}} \mathrm{n}^{1}$
}

To cite: Zhang $\mathrm{H}$, Sun $\mathrm{H}$. Knowledge, attitude and selfefficacy of elderly caregivers in Chinese nursing homes: a cross-sectional study in Liaoning Province. BMJ Open 2019:9:e029869. doi:10.1136/ bmjopen-2019-029869

- Prepublication history and additional material for this paper are available online. To view these files, please visit the journal online (http://dx.doi. org/10.1136/bmjopen-2019029869).

Received 19 February 2019 Revised 05 October 2019 Accepted 22 October 2019

Check for updates

(C) Author(s) (or their employer(s)) 2019. Re-use permitted under CC BY-NC. No commercial re-use. See rights and permissions. Published by BMJ.

${ }^{1}$ School of Pharmaceutical Science and Technology, Tianjin University, Tianjin, China

${ }^{2}$ School of Nursing, Jinzhou Medical University, Jinzhou, China

Correspondence to

Dr He Sun;

18768429445@163.com

\section{ABSTRACT}

Objective This study aimed to investigate the perceptions of elderly caregivers in Chinese nursing homes (NHs) and associated factors with regard to knowledge, attitude about elderly and self-efficacy.

Setting A cross-sectional questionnaire survey was conducted in $12 \mathrm{NHs}$ in Liaoning Province, China. Participants A total of 403 caregivers from $12 \mathrm{NHs}$ were surveyed.

Outcome measures Data were collected using a selfadministered questionnaire composed of the Palmore's Facts on Aging Quiz I, Kogan's Attitude Towards Old People Scale, General Self-Efficacy Scale and background characteristics of participants. An average score for knowledge, attitude and self-efficacy was calculated. Differences across groups were evaluated using Student's t-test and analysis of variance. Multivariable linear regression models were established to estimate the associated factors.

Results The participating caregivers reported a relative low score on knowledge about the elderly (10.42 \pm 2.79$)$, attitude towards old people $(127.85 \pm 14.36)$ and selfefficacy (27.12 \pm 4.9$)$. Multivariable regression analysis showed that respondents who had high educational level ( $\beta=0.212,95 \% \mathrm{Cl} 0.193$ to 0.824 ), received prejob training $(\beta=0.193,95 \% \mathrm{Cl} 0.081$ to 1.169$)$ and had high job satisfaction (general satisfaction: $\beta=0.345,95 \% \mathrm{Cl} 0.223$ to 1.875 ; very satisfied: $\beta=0.322,95 \% \mathrm{Cl} 0.210$ to 1.283 ) gave a positive rating on knowledge. Caregivers who were employed as formal staff $(\beta=0.155,95 \% \mathrm{Cl} 0.116$ to 1.670$)$, earned a high income $(\beta=0.214,95 \% \mathrm{Cl} 0.117$ to 1.461 ) and had an interest in working with the elderly ( $\beta=0.141,95 \% \mathrm{Cl} 0.088$ to 1.508 ) tended to develop a positive attitude towards the elderly. However, caregivers who were female $(\beta=-0.110,95 \% \mathrm{Cl}-1.751$ to -0.080$)$ and had long work experience $(\beta=-0.130,95 \% \mathrm{Cl}-1.527$ to -0.110 ) developed negative perception. Caregivers who were older ( $\beta=0.215,95 \% \mathrm{Cl} 0.139$ to 1.027 ), received prejob training ( $\beta=0.143,95 \% \mathrm{Cl} 0.113$ to 1.024$)$, had an interest in working with the elderly $(\beta=0.154,95 \% \mathrm{Cl}$ 0.114 to 1.015$)$, had high job satisfaction $(\beta=0.177$, $95 \% \mathrm{Cl} 0.116$ to 1.223 ) and perceived better health status for the elderly (partial disability: $\beta=0.437,95 \% \mathrm{Cl} 0.259$ to 1.600; no disability: $\beta=0.288,95 \% \mathrm{Cl} 0.153$ to 1.211 ) gave a positive rating on self-efficacy.

Conclusion Knowledge about the elderly, attitude towards old people and self-efficacy of elderly caregivers in Chinese

\section{Strengths and limitations of this study}

- This study is among the first to understand the perception of caregivers in Chinese nursing homes on knowledge about ageing, attitude towards the elderly and self-efficacy.

- Multivariable linear regression models were established and used to identify multifaceted factors associated with the perceived knowledge, attitude and self-efficacy of caregivers.

- Using widely accepted scales (Facts on Aging Quiz I, Kogan's Attitude Towards Old People Scale and General Self-Efficacy Scale) for data collection contributed to the reliability of the results.

- The samples were collected from only one province located in the north-eastern region of China.

- Caution needs to be taken when generalising the findings to China or other countries.

$\mathrm{NHs}$ were at low levels. Some targeted intervention programmes, such as conducting professional training for aged care and a performance-based payment system, should be given priority to improve these attributes.

\section{INTRODUCTION}

Population ageing has been given increased attention worldwide, especially in China. According to the National Bureau of Statistics of China (2017), the elderly population aged 60 years and higher has reached 240 million, accounting for $17.3 \%$ of the total population. ${ }^{12}$ By 2050, this number is expected to increase up to 450 million, accounting for $33 \%$ of the total population. ${ }^{3}$ Hence, China will become the country with the largest number of old people in the world. Such growth in population ageing will result in a significantly increased need for long-term care.

Influenced by traditional Chinese culture, elderly people prefer to live with their children, and taking care of the elderly is regarded as the responsibility of the family. ${ }^{4}$ However, the increasing migration from rural to urban 
areas, especially among young people, and the shrinking average family size due to China's one-child policy ${ }^{5}$ have changed the mainstream, informal, family-based caregiving model for older adults. Consequently, old people are being sent to nursing homes (NHs) for professional aged care.

Over the past few years, the Chinese government made a great effort to support the development of the aged care service industry and invested into NHs. Approximately 155000 different types of NHs exist across Mainland China, and include old age homes, retirement departments, residential care facilities, welfare institutes and geriatric hospitals. However, NHs have shortage of health workers, or their health workers lack formal vocational training. ${ }^{3}$ As a result, low-level caregiving skills and poor healthcare quality have become an urgent issue and have attracted a wide range of attention. ${ }^{78}$ Although the Chinese government launched the 'Basic Standards for Service Quality of Aged Agencies' in 2017, the quality of nursing services for the elderly is still not guaranteed. ${ }^{9}$ Providing high-quality aged care services seems to pose a huge challenge in coping with China's ageing society.

Elderly caregivers in NHs, as the front-line healthcare workers, spend considerable time with old people and have a direct effect on healthcare delivery. ${ }^{10}$ However, holding a negative attitude and misunderstanding about ageing often create an adverse impact on provision of healthcare behaviour and ultimately lead to poor health outcomes. ${ }^{11}{ }^{12}$ In addition to attitude and knowledge, selfefficacy, which is defined as 'people's beliefs about their capabilities to exercise control over events that affect their lives', ${ }^{13}$ is another widely recognised factor associated with health workers' behaviour in care delivery. In general, high self-efficacy is associated with positive feelings about one's self, which facilitate cognitive processes and work achievement, as well as confidence and motivation. ${ }^{14}$ Therefore, giving an emphasis on the knowledge, attitude and self-efficacy of caregivers is beneficial in providing high-quality aged care services.

Many studies conducted in Western countries revealed that social workers, healthcare workers and nursing students tend to have poor attitude, misconception, inadequate knowledge and lowest priority to consider working with the elderly. ${ }^{15-18}$ However, there is paucity in the literature in low-income and middle-income Asian countries, including China. Understanding the knowledge, attitude and self-efficacy of elderly caregivers in NHs and the significant increase in the need for aged care in China has practical significance.

This study aimed to investigate the perceptions of caregivers on knowledge about ageing, attitude towards the elderly and self-efficacy and their associated factors.

\section{METHODS}

\section{Setting and sampling}

A cross-sectional quantitative survey was conducted in Liaoning Province, located in the north-eastern region of China, where people aged over 60 years account for $22.65 \%$ of the total population. ${ }^{19}$

We adopted a multistage sampling strategy. First, three cities were selected from three different geographical zones, namely Shenyang representing the central zone, Jinzhou representing the west and Dandong representing the east. Four NHs (two were large-sized, two were smallsized) were selected randomly in each city according to their organisation code. Twelve NHs were selected to participate. Finally, half of the caregivers were considered as samples in each selected $\mathrm{NH}$.

Data were collected from 1 November 2015 to 31 May 2016. Two to four trained investigators assigned to each selected NH were required to invite caregivers working in different departments. The participants were asked to provide informed consent letter and oral consent before they filled in the questionnaires, and the questionnaires were given to the investigators right after completion. We approached potential participants across the entire working time and selected half of caregivers in each $\mathrm{NH}$ to maximise the chance of capturing a representative sample.

Considering that $\mathrm{NH}$ has no standardised definition in Mainland China, this study defined it as an institution included in residential long-term care facilities in Mainland China that mainly admits people aged 60 years or older. A qualified elderly caregiver usually needs to receive 3-5 years of professional training in China. In this study, caregivers who had direct contact with the elderly were eligible to participate in the investigation. These caregivers included physicians, nurses and allied health workers. Participants should have worked in the selected NHs for more than 1 year and voluntarily participated in the survey.

Approximately 800 caregivers were invited to participate in this investigation, and 480 participants $(60 \%)$ filled in and returned the questionnaires. We recorded the reasons for non-participation. Overall, these people had an idea about the purpose of our study or have no time to participate in the survey. After excluding questionnaires with uncompleted key items, 403 (83.9\%) were considered valid for data analysis (figure 1). The $\alpha$ level (type I error rate) at 0.05 and $\beta$ level (statistical power) at 0.8 were used to conduct a power analysis. We found such sample size is large enough for data analysis. According to the formula proposed by Peduzzi $e t a l,{ }^{20}{ }^{21}$ the minimum sample size is at least $10 \times K$, where $K$ is the number of predictors in the regression model. This sample size would also be sufficiently large for multivariable linear regression analyses for a model containing 18 dichotomous independent variables (table 1).

\section{Measurement}

We adopted Palmore's Facts on Aging Quiz I (FAQ 1), Kogan's Attitude Towards Old People Scale (KAOP) and General Self-Efficacy Scale (GSE) to measure knowledge about old people, attitude towards the elderly and selfefficacy of caregivers, respectively. Data about the characteristics of the caregivers and their work environments were also collected using a self-developed questionnaire. 


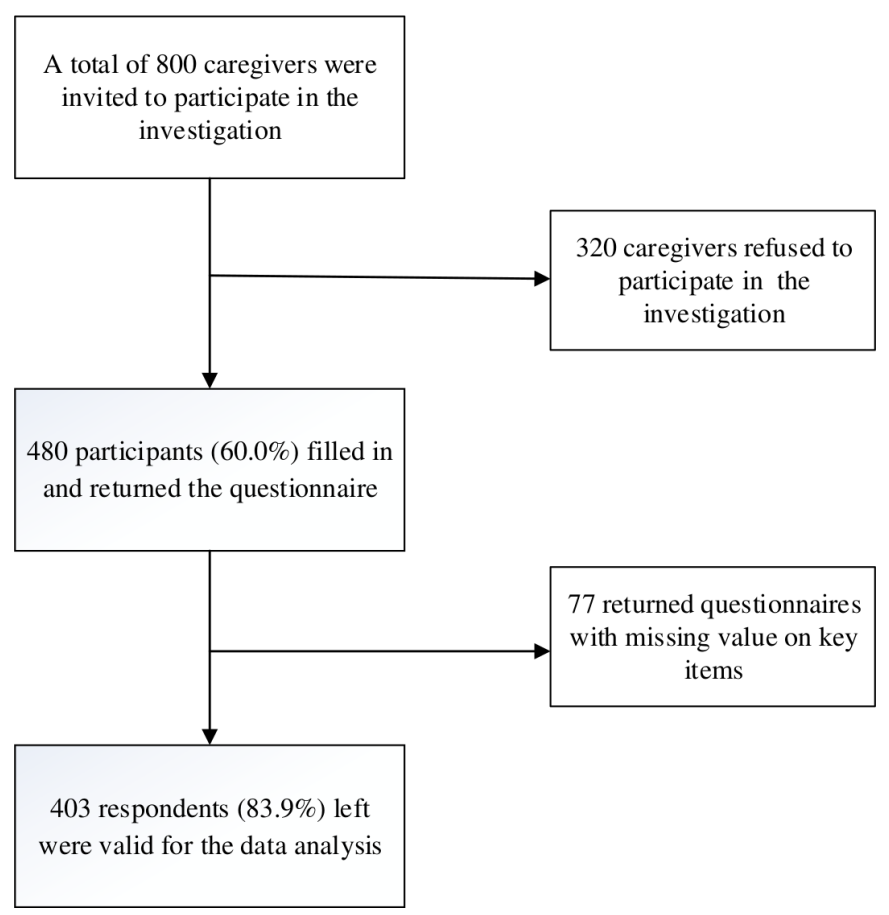

Figure 1 The process of sample screening. 800 samples were filtered to 403 .

FAQ 1, developed by Palmore in $1977^{22}$, has been widely used to assess subjects' (including caregivers) physical, mental and social knowledge about ageing, as well as some of the most common misconceptions about ageing. ${ }^{15}{ }^{23}$ FAQ 1 is composed of 25 statements, such as 'old people tend to react slower than young people' and 'old people are not as efficient as young people'. The participants responded by stating whether a statement is true (T) or false (F); a score of 1 is assigned if the answer is right, otherwise the score is 0 . Therefore, the total scores range from 0 to 25 , with a high score representing high knowledge about the elderly. The Chinese version of FAQ 1, introduced by Wang $e t a l,{ }^{24}$ has adequate reliability (Cronbach's $\alpha=0.68$ ).

KAOP, which was developed by Kogan in $1961,{ }^{25}$ has been used to measure attitude towards the elderly in many studies. This scale contains 34 items, with 17 negative (KAOP-) and 17 positive (KAOP+) statements. Examples of the statements are as follows: 'most of the elderly gets set in their ways and are unable to change' and 'it is very easy to get on with the elderly'. Each item is scored using a 6-point Likert scale (strongly disagree $=1$, disagree $=2$, slightly disagree $=3$, slightly agree $=5$ and strongly agree $=6$ ). The scores on the statement presented negatively should be reversed to estimate the total score. The total scores for KAOP range from 34 to 204, with high scores representing positive attitude towards the elderly. ${ }^{26}$ For the Chinese version of KAOP, the Cronbach's $\alpha$ is 0.82 for the total scale, indicating that it is a fully reliable instrument. ${ }^{27}$

GSE, which was developed by Zhang and Schwarzer in $1995,{ }^{28}$ is used widely to measure a general sense of perceived self-efficacy. ${ }^{29}$ The 10 items of the GSE are scored on a 4-point scale (not at all true $=1$, hardly true $=2$, moderately true $=3$ and exactly true $=4$ ). The total scores range from 10 to 40 , with a high score indicating high self-efficacy. A Cronbach's $\alpha$ value of 0.89 for the Chinese version of the GSE indicates that this instrument has high reliability for the study population. ${ }^{2}$

In the last part of the questionnaire, some close-ended questions were designed to collect information about the background characteristics of the participating caregivers and their work environment. General demographic characteristics including age, gender and educational level were also investigated (table 1). Various questions about caregivers' work environment were also asked. These questions include the following examples: 'how many years have you been working in this NH (work tenure)' and 'is your $\mathrm{NH}$ public or private (ownership of $\mathrm{NH}$ ); located in rural or urban (work place)' (table 1). The employment type of caregivers in Chinese NHs includes formal and informal employees. Formal employees are hired by the government, and their wages are paid by the National Finance Department. Informal employees are caregivers who signed the labour contract with NHs, and their wages come from the profits of the institution. ${ }^{30}$ We also obtained information on prejob training (yes/ no), interest in working with the elderly (yes/no) and job satisfaction (not/generally/very satisfied). Meanwhile, we measured caregivers' perceived health status of the elderly by asking 'how rate overall health status of the elderly in NHs (complete/partial/with no disability)' (table 1). These factors were identified as independent variables in the regression model. ${ }^{1531} 32$

\section{Data analysis}

Scores on each item of FAQ 1, KAOP and GSE were added. According to the guidance on the use of each scale, every item was given the same weight. ${ }^{24} 2933$ The average score was calculated to evaluate the levels of knowledge, attitude and self-efficacy.

The Kolmogorov-Smirnov test showed that the p values for knowledge, attitude and self-efficacy scores exceeded 0.10 ; as such, data of these variables were normally distributed. Student's t-test (for two-group comparisons) or analysis of variance (for multiple group comparisons) was performed to determine statistical differences in scores across different groups. Multivariable linear regression models were established to identify factors associated with knowledge, attitude and self-efficacy scores, and serving the characteristics of respondents as independent variables.

In model establishment, we used the ENTER approach (all independent variables are forced into the regression models) due to two reasons: first, we tend to explain the variations in knowledge, attitude and self-efficacy scores instead of predicting them. This approach allowed us to observe the parameters of these factors that are not significantly associated with the dependent variables. Second, all independent variables in the model have been studied in other countries. ${ }^{15} 31$ To compare our results with those reported in other countries, we added 
Open access

Table 1 Differences in knowledge, attitude and self-efficacy scores among different characteristics of caregivers

\begin{tabular}{|c|c|c|c|c|c|c|c|}
\hline \multirow[b]{2}{*}{ Variables } & \multirow[b]{2}{*}{ n (\%) } & \multicolumn{2}{|c|}{ FAQ 1 scores } & \multicolumn{2}{|l|}{ KAOP scores } & \multicolumn{2}{|c|}{ Self-efficacy scores } \\
\hline & & Mean \pm SD & $P$ value & Mean \pm SD & $P$ value & Mean \pm SD & $P$ value \\
\hline Gender & & & 0.055 & & 0.034 & & 0.890 \\
\hline Male & $41(10.2)$ & $11.22 \pm 3.09$ & & $132.30 \pm 15.75$ & & $27.02 \pm 4.21$ & \\
\hline Female & $362(89.8)$ & $10.33 \pm 2.75$ & & $127.31 \pm 14.13$ & & $27.13 \pm 4.98$ & \\
\hline Age (years) & & & 0.070 & & 0.909 & & 0.004 \\
\hline 30-39 & $119(29.5)$ & $10.37 \pm 2.70$ & & $128.22 \pm 14.13$ & & $26.33 \pm 4.19$ & \\
\hline $40-49$ & $141(35.0)$ & $10.83 \pm 2.96$ & & $127.93 \pm 15.07$ & & $26.70 \pm 5.41$ & \\
\hline$\leq 50$ & $143(35.5)$ & $10.07 \pm 2.66$ & & $127.45 \pm 13.93$ & & $28.18 \pm 4.79$ & \\
\hline Educational level & & & 0.046 & & 0.276 & & 0.927 \\
\hline Junior high school or below & $225(55.8)$ & $10.23 \pm 2.90$ & & $126.93 \pm 13.78$ & & $27.09 \pm 4.83$ & \\
\hline Secondary high school & $96(23.8)$ & $11.04 \pm 2.77$ & & $129.72 \pm 14.08$ & & $27.03 \pm 5.20$ & \\
\hline Bachelor's degree or above & $82(20.3)$ & $10.23 \pm 2.44$ & & $128.16 \pm 16.11$ & & $27.30 \pm 4.81$ & \\
\hline Work tenure (years) & & & 0.858 & & 0.172 & & 0.355 \\
\hline $1-3$ & $222(55.1)$ & $10.47 \pm 2.87$ & & $129.70 \pm 15.43$ & & $27.44 \pm 5.02$ & \\
\hline $4-6$ & $114(28.3)$ & $10.44 \pm 2.81$ & & $128.55 \pm 10.61$ & & $26.76 \pm 4.64$ & \\
\hline$\leq 7$ & 67 (16.6) & $10.25 \pm 2.53$ & & $126.68 \pm 14.72$ & & $26.68 \pm 4.96$ & \\
\hline Nursing home ownership & & & 0.033 & & 0.032 & & 0.708 \\
\hline Public & $132(32.8)$ & $14.24 \pm 2.99$ & & $133.94 \pm 15.91$ & & $26.99 \pm 4.61$ & \\
\hline Private & $271(67.2)$ & $10.51 \pm 2.69$ & & $127.80 \pm 13.58$ & & $27.18 \pm 5.05$ & \\
\hline Workplace & & & 0.127 & & 0.862 & & 0.296 \\
\hline Urban & $249(61.8)$ & $10.26 \pm 2.84$ & & $127.94 \pm 15.20$ & & $27.32 \pm 4.96$ & \\
\hline Rural & $154(38.2)$ & $10.69 \pm 2.71$ & & $127.69 \pm 12.95$ & & $26.78 \pm 4.82$ & \\
\hline Employment type & & & 0.037 & & 0.011 & & 0.042 \\
\hline Informal employee & $350(86.8)$ & $10.24 \pm 2.81$ & & $127.05 \pm 14.20$ & & $25.33 \pm 4.47$ & \\
\hline Formal employee & $53(13.2)$ & $15.40 \pm 2.56$ & & $135.63 \pm 15.96$ & & $27.66 \pm 5.22$ & \\
\hline Monthly income (¥) & & & 0.466 & & $<0.001$ & & 0.975 \\
\hline$<2000$ & $160(39.7)$ & $10.21 \pm 2.81$ & & $126.52 \pm 15.21$ & & $27.05 \pm 5.24$ & \\
\hline 2000-3000 & $200(49.6)$ & $10.56 \pm 2.74$ & & $127.13 \pm 12.71$ & & $27.16 \pm 4.91$ & \\
\hline$>3000$ & $43(10.7)$ & $10.60 \pm 3.00$ & & $136.11 \pm 15.59$ & & $27.18 \pm 3.51$ & \\
\hline Prejob training & & & 0.040 & & 0.106 & & 0.001 \\
\hline No & $129(32.0)$ & $10.01 \pm 2.95$ & & $126.16 \pm 14.38$ & & $25.91 \pm 4.62$ & \\
\hline Yes & $274(68.0)$ & $10.62 \pm 2.70$ & & $128.64 \pm 14.31$ & & $27.69 \pm 4.94$ & \\
\hline Health status of the elderly & & & 0.868 & & 0.602 & & $<0.001$ \\
\hline Complete disability & $34(8.4)$ & $10.21 \pm 2.21$ & & $125.49 \pm 14.11$ & & $26.32 \pm 4.34$ & \\
\hline Partial disability & $219(54.3)$ & $10.42 \pm 2.79$ & & $127.98 \pm 13.50$ & & $27.62 \pm 5.17$ & \\
\hline No disability & $150(37.2)$ & $10.49 \pm 2.92$ & & $128.19 \pm 15.63$ & & $30.64 \pm 5.41$ & \\
\hline Interest in working with elder & ly people & & 0.273 & & 0.019 & & 0.022 \\
\hline No & $58(14.4)$ & $9.88 \pm 2.72$ & & $123.74 \pm 14.15$ & & $25.68 \pm 4.66$ & \\
\hline Yes & $344(85.4)$ & $10.51 \pm 2.80$ & & $128.60 \pm 14.28$ & & $27.34 \pm 4.91$ & \\
\hline Job satisfaction & & & 0.001 & & 0.033 & & 0.001 \\
\hline Not satisfied & $34(8.4)$ & $8.68 \pm 2.77$ & & $121.97 \pm 16.80$ & & $25.14 \pm 5.42$ & \\
\hline Generally satisfied & $151(37.5)$ & $10.66 \pm 2.49$ & & $127.70 \pm 13.29$ & & $26.42 \pm 4.94$ & \\
\hline Very satisfied & $218(54.1)$ & $10.54 \pm 2.91$ & & $128.86 \pm 14.51$ & & $27.91 \pm 4.66$ & \\
\hline
\end{tabular}

FAQ 1, Facts on Aging Quiz I; KAOP, Kogan's Attitude Towards Old People Scale. 
all independent variables into the regression model. In order to assess fit of the regression models, we used plots of residuals against the covariates (online supplementary figures 1-3). We also conducted logistic regression analyses for sensitivity test by recoding the knowledge, attitude and self-efficacy scores into dichotomous variables (online supplementary table).

A double-entry strategy was adopted to ensure the accuracy of data input using EpiData V.3.1. All statistical analyses were performed using IBM SPSS Statistics V.22.0.

\section{Patient and public involvement}

This study focused on knowledge about ageing, attitude towards the elderly and self-efficacy; thus, patients were not directly involved in the survey.

\section{RESULTS}

\section{Characteristics of respondents}

Of the 403 respondents, $89.8 \%$ were female. A total of $70.5 \%$ of the respondents were aged more than 40 years. Only $20.3 \%$ of the caregivers had bachelor's degree or above. More than half of the respondents had working tenure of $<3$ years $(55.1 \%)$ and worked in urban setting $(61.8 \%)$. The majority of the participants $(86.8 \%)$ were employed as informal employees. Only $10.7 \%$ earned a monthly income of $>¥ 3000$. A total of $68.0 \%$ and $85.4 \%$ of the respondents reported that they received prejob training and had an interest in elderly care, respectively (table 1).

\section{Knowledge, attitude towards the elderly and self-efficacy}

Overall, relatively low scores for knowledge (10.42 \pm 2.79$)$, attitude (127.85 \pm 14.36$)$ and self-efficacy (27.12 \pm 4.91$)$ were measured by FAQ 1, KAOP and GSE, respectively, among caregivers in NHs.

Table 1 shows the differences in the scores of knowledge, attitude and self-efficacy rated by caregivers with different characteristics. Male respondents gave higher scores on attitude than female ones $(p<0.05)$. Older caregivers showed higher self-efficacy than younger ones $(p<0.05)$. Respondents with middle educational level gave higher scores on knowledge than the other two groups $(\mathrm{p}<0.05)$. Caregivers working in public NHs had high scores on knowledge and attitude $(\mathrm{p}<0.05)$. Formal employees showed better performance in terms of knowledge, attitude and self-efficacy $(\mathrm{p}<0.05)$. Scores for attitude increased with increasing monthly salary $(\mathrm{p}<0.001)$. Participants who received prejob training reported high scores for knowledge and self-efficacy $(\mathrm{p}<0.05)$. Respondents interested in elderly care gave high scores for attitude and self-efficacy $(p<0.05)$. Scores for the three domains varied across different job satisfaction levels $(\mathrm{p}<0.05)$.

Factors associated with knowledge, attitude and self-efficacy: results of multivariable linear regression analyses

Table 2 shows the results of the three multivariable linear regression models for analysis of factors associated with knowledge, attitude and self-efficacy.
Knowledge about older people

Respondents with bachelor's degree or above $(\beta=0.212$, 95\% CI 0.193 to 0.824 ) gave higher scores in FAQ 1 than those who completed junior high school or below. People who received prejob training $(\beta=0.193,95 \%$ CI 0.081 to $1.169)$ were more likely to report high scores for knowledge, but there could be uncertainty in the result due to a wide CI. Those who were generally satisfied $(\beta=0.345$, $95 \%$ CI 0.223 to 1.875$)$ and very satisfied $(\beta=0.322,95 \%$ CI 0.210 to 1.283 ) with their jobs also gave a positive rating on knowledge.

\section{Attitudes towards older people}

The attitude scores in KAOP were high for those who were employed as formal employee $(\beta=0.155,95 \%$ CI 0.116 to 1.670$)$, earned high wages $(\beta=0.214,95 \%$ CI 0.117 to $1.461)$ and had an interest in working with aged people $(\beta=0.141,95 \%$ CI 0.088 to 1.508$)$. However, it was assumed that the association between KAOP scores and interest in working with aged people was not stable because the $95 \%$ CI was relatively wide. Additionally, female $(\beta=-0.110$, $95 \%$ CI -1.751 to -0.080 ) and respondents with more than 7 years of work experience $(\beta=-0.130,95 \% \mathrm{CI}-1.527$ to -0.110 ) reported low scores.

\section{Self-efficacy}

A high self-efficacy score in GSE was observed in caregivers who were older $(\beta=0.215,95 \%$ CI 0.139 to 1.027$)$, received prejob training $(\beta=0.143$, 95\% CI 0.113 to 1.024$)$, had an interest in working with the elderly $(\beta=0.154,95 \%$ CI 0.114 to 1.015$)$ and had high job satisfaction $(\beta=0.177$, $95 \%$ CI 0.116 to 1.223 ). In addition, better health status of the elderly (partial disability: $\beta=0.437,95 \%$ CI 0.259 to 1.600 ; no disability: $\beta=0.288$, $95 \%$ CI 0.153 to 1.211 ) caregivers served was also significantly associated with selfefficacy scores.

A moderate association ${ }^{34}$ between knowledge and attitude scores $(\mathrm{r}=0.233, \mathrm{p}<0.05)$ and between attitude and self-efficacy scores $(\mathrm{r}=0.150, \mathrm{p}<0.05)$ was tested by Pearson correlation calculations. The correlation coefficient between knowledge and self-efficacy was not statistically significant $(r=0.034, \mathrm{p}>0.05)$.

\section{DISCUSSION}

The increasing elderly population has led to challenges for the Chinese government in meeting the increasing need for professional healthcare for aged people. This study assessed the knowledge and attitude about ageing and the self-efficacy of caregivers working in Chinese NHs. Low levels of knowledge, attitude and self-efficacy were observed in the present study compared with those in other countries or regions. ${ }^{31} 33$ At the initial stage of NH development in China, severe shortage of qualified health workers and insufficient professional training resulted in difficulties of the majority of caregivers in providing healthcare services for the elderly. ${ }^{3}$ Low income and negative expectation for career development 
Open access

Table 2 Factors associated with knowledge, attitude and self-efficacy: multivariable linear regression models

\begin{tabular}{|c|c|c|c|c|c|c|c|c|c|}
\hline \multirow[b]{2}{*}{ Variables } & \multicolumn{3}{|c|}{ FAQ 1 scores } & \multicolumn{3}{|c|}{ KAOP scores } & \multicolumn{3}{|c|}{ Self-efficacy scores } \\
\hline & $\beta$ & $95 \% \mathrm{Cl}$ & $P$ value & $\beta$ & $95 \% \mathrm{Cl}$ & $P$ value & $\beta$ & $95 \% \mathrm{Cl}$ & $P$ value \\
\hline \multicolumn{10}{|l|}{ Gender } \\
\hline Female & -0.081 & -1.646 to 0.176 & 0.102 & -0.110 & -1.751 to 0.080 & 0.022 & 0.010 & -1.169 to 1.813 & 0.812 \\
\hline \multicolumn{10}{|l|}{ Age (years) } \\
\hline$\geq 50$ & -0.011 & -0.951 to 0.619 & 0.731 & -0.013 & -5.362 to 2.750 & 0.534 & 0.215 & 0.139 to 1.027 & 0.003 \\
\hline \multicolumn{10}{|l|}{ Educational level } \\
\hline Junior high school or below & Ref & & & Ref & & & Ref & & \\
\hline Secondary high school & 0.100 & -0.019 to 1.391 & 0.057 & 0.071 & -1.207 to 5.078 & 0.160 & 0.014 & -1.086 to 1.331 & 0.771 \\
\hline \multicolumn{10}{|l|}{ Working tenure (years) } \\
\hline $4-6$ & -0.006 & -0.601 to 0.520 & 0.923 & 0.093 & -0.379 to 4.053 & 0.061 & -0.079 & -1.105 to 0.129 & 0.065 \\
\hline$\geq 7$ & -0.051 & -1.231 to 0.441 & 0.290 & -0.130 & -1.527 to 0.110 & 0.044 & -0.058 & -1.146 to 0.378 & 0.304 \\
\hline \multicolumn{10}{|l|}{ NH ownership } \\
\hline Public & Ref & & & Ref & & & Ref & & \\
\hline Private & 0.062 & -0.317 to 0.570 & 0.413 & -0.041 & -1.427 to 1.127 & 0.784 & 0.067 & -0.408 to 1.001 & 0.202 \\
\hline \multicolumn{10}{|l|}{ Workplace } \\
\hline Urban & Ref & & & Ref & & & Ref & & \\
\hline Rural & 0.062 & -0.065 to 0.787 & 0.186 & -0.032 & -1.617 to 1.211 & 0.063 & -0.013 & -0.873 to 0.739 & 0.706 \\
\hline \multicolumn{10}{|l|}{ Employment type } \\
\hline \multicolumn{10}{|l|}{ Prejob training } \\
\hline No & Ref & & & Ref & & & Ref & & \\
\hline Yes & 0.193 & 0.081 to 1.169 & 0.043 & 0.046 & -1.311 to 4.360 & 0.315 & 0.143 & 0.113 to 1.024 & 0.002 \\
\hline \multicolumn{10}{|l|}{ Health status of elderly } \\
\hline Complete disability & Ref & & & Ref & & & Ref & & \\
\hline Partial disability & 0.004 & -1.002 to 0.894 & 0.917 & 0.114 & -1.885 to 8.457 & 0.214 & 0.437 & 0.259 to 1.600 & $<0.001$ \\
\hline No disability & 0.011 & -1.069 to 1.026 & 0.410 & 0.084 & -2.931 to 7.759 & 0.362 & 0.288 & 0.153 to 1.211 & 0.001 \\
\hline \multicolumn{10}{|l|}{ Interest in working with elderly } \\
\hline No & Ref & & & Ref & & & Ref & & \\
\hline Yes & 0.080 & -0.358 to 1.230 & 0.122 & 0.141 & 0.088 to 1.508 & 0.039 & 0.154 & 0.114 to 1.015 & 0.012 \\
\hline \multicolumn{10}{|l|}{ Job satisfaction } \\
\hline Not satisfied & Ref & & & Ref & & & Ref & & \\
\hline Generally satisfied & 0.345 & 0.223 to 1.875 & $<0.001$ & 0.079 & -1.293 to 3.108 & 0.323 & 0.052 & -1.103 to 2.469 & 0.572 \\
\hline Very satisfied & 0.322 & 0.210 to 1.283 & $<0.001$ & 0.098 & -1.108 to 3.275 & 0.388 & 0.177 & 0.116 to 1.223 & 0.043 \\
\hline$F$ & 2.478 & & 0.001 & 2.744 & & 0.001 & 3.848 & & $<0.001$ \\
\hline$R^{2}$ & 0.118 & & & 0.122 & & & 0.161 & & \\
\hline Adjusted $R^{2}$ & 0.105 & & & 0.109 & & & 0.155 & & \\
\hline
\end{tabular}

Figures in bold indicate coefficients with statistical significance. 500 bootstrapping replications were used.

FAQ I, Facts on Aging Quiz I; KAOP, Kogan's Attitude Towrads Old People Scale; NH, nursing home; Ref, reference. 
also adversely influenced the work performance of caregivers. ${ }^{36}$

Consistent with other studies, ${ }^{1833} 37$ the present results found that caregivers who received higher level education and prejob training gave higher scores for knowledge about the elderly. A possible reason is that long-term education improved the working ability of caregivers, and can also teach additional knowledge and further correct their misunderstanding about ageing. Despite the association of knowledge scores with prejob training being significant in our model, this result could not be stable and needs further research. It may be due to the effect of short-term training being not significant. In addition to the two factors, high job satisfaction level was also associated with knowledge, given that this driving force factor can encourage staff to learn additional information relative to their work. ${ }^{38}$

With respect to attitude towards the elderly, this study indicated that women were more likely to have negative attitude compared with men, inconsistent with other studies. ${ }^{1539}$ The potential explanation is that women in Chinese traditional families take additional responsibilities in cultivating children and taking care of old people; as such, female caregivers tend to develop poor attitude. Additionally, gender discrimination in the workplace often results in unequal treatment for women in terms of wages and career advancement. ${ }^{40} 41$ Therefore, female caregivers tend to have poor attitude. The negative association of work tenure with attitude can be explained by the fact that long-term work in the same position can result in burn-out, ${ }^{42}$ leading to negative emotion towards work.

Similar to another study, ${ }^{43}$ caregivers employed as formal staff had positive attitude towards the elderly than informal employees. This finding could be mainly due to the unequal salary system in Chinese NHs. Considering that the wages of formal employees are paid by government revenues, they often obtain more benefits (such as social insurances) than the others, although they have the same workload. ${ }^{44}$ Therefore, a performance-based pay system can be considered to encourage caregivers to develop a positive attitude. For example, old people's satisfaction with service can be used as a performance evaluation indicator; an equal payment system for informal and formal employees should be designed.

Additionally, the KAOP scores increased with increasing income, reflecting the important role of economic factors in improving the work enthusiasm and performance of caregivers. ${ }^{45}$ Although caregivers interested in working with the elderly tended to have positive attitude in this study, there is uncertainty in the result, possibly due to the fact that the effects of other factors (such as burn-out, work stress) are not controlled. ${ }^{4647}$

In this study, the age of caregivers had a positive relationship to self-efficacy, consistent with previous results. ${ }^{48}$ Old age often indicates an increase in life and work experiences, and accordingly improved people's beliefs about their capabilities. Caregivers who received prejob training are expected to possess improved work skills in handling workload and overcoming obstacles, thereby enhancing their self-perception on personal efficacy. ${ }^{49}$ Therefore, professional training for aged care should be conducted to improve the knowledge and abilities of caregivers.

The perceived health status of the elderly evaluated by caregivers is also responsible for the variations in self-efficacy scores. Providing services for the old adults without disability decreases difficulty for caregivers compared with caring for disabled ones. ${ }^{50}$ Thus, this group of caregivers is more likely to perceive a high level of self-efficacy. Meanwhile, the positive association of selfefficacy with interest in working with old people and job satisfaction indicated these factors can evoke enthusiastic attitude towards work, thereby improving self-confidence in coping with work difficulties.

The positive correlations among knowledge, attitude and self-efficacy presented in this study agreed with the 'knowledge-attitude-practice' theory. ${ }^{51}{ }^{52}$ Knowing the correct knowledge about ageing is beneficial for caregivers to develop an optimistic attitude towards elderly people. ${ }^{51}$ Accordingly, positive attitude is beneficial in improving people's beliefs about their capabilities. ${ }^{52}$ Therefore, these closed associations indicated that an effective workforce management for caregivers should take knowledge, attitude and self-efficacy into account.

\section{Limitation}

This study has several limitations. First, the 403 samples from Liaoning Province were limited to reflect the comprehensive situation in China. This sample size also affected the width of $95 \% \mathrm{CI}$ in the regression models, although it is sufficient for data analysis. Caution needs to be taken when generalising the findings. Second, exploratory variables mainly included demographics and working environment characteristics of caregivers, although the selection of these variables was supported by previous studies and interviews. However, institutionallevel factors potentially influencing the perceptions of caregivers, such as the number of employees and elderly in NHs, were ignored because data are unavailable. As such, the $R^{2}$ of the regression models was relatively low. Therefore, further studies should cover factors at different levels. As the outcome measurement is not on an interval scale, there may be concern about using linear regression in the main analyses. However, we obtained similar results in a sensitivity analysis using logistic regression with a cut point at the mean for each score, and so this provides some support for the approach used. Third, readers should be aware that participants may report what they believe the researcher wants to know instead of the truth. Hence, the use of a self-report questionnaire could lead to idealised responses to meet socially acceptable norms.

\section{CONCLUSION}

This study provides some insights into the knowledge, attitude about the elderly and self-efficacy of caregivers in 
Chinese NHs and identify their associated characteristics and work environment factors.

Overall, caregivers working in Chinese NHs have a poor rating on knowledge about ageing, attitude towards the elderly and self-efficacy. Factors associated with these attributes mainly include gender, age, educational level, income, working tenure, employment type, prejob training, health status of elderly, interest in working with elderly and job satisfaction.

Acknowledgements The authors gratefully acknowledge all interviewees participating in this study.

Contributors Both authors made significant contributions to the study. $\mathrm{HZ}$ conceptualised this study and analysed the data. Moreover, she wrote the first draft of the manuscript. HS interpreted the results and revised the manuscript. The final version submitted for publication was read and approved by both authors.

Funding This work was supported by Liaoning Provincial Social Science Project (no 2019lslktyb-067).

Competing interests None declared.

Patient consent for publication Not required.

Ethics approval The study was approved by the ethics committee of Jinzhou Medical University (JMU00001078-15088).

Provenance and peer review Not commissioned; externally peer reviewed. Data availability statement Data are available upon reasonable request.

Open access This is an open access article distributed in accordance with the Creative Commons Attribution Non Commercial (CC BY-NC 4.0) license, which permits others to distribute, remix, adapt, build upon this work non-commercially, and license their derivative works on different terms, provided the original work is properly cited, appropriate credit is given, any changes made indicated, and the use is non-commercial. See: http://creativecommons.org/licenses/by-nc/4.0/.

\section{REFERENCES}

1 Wu M, Li SX, Zhang NJ, et al. Nursing home research in Jinan, China: a focus group approach. Int J Public Pol 2012;8:21-30.

2 Fu F, Liang Y, An Y, et al. Self-Efficacy and psychological well-being of nursing home residents in China: the mediating role of social engagement. Asia Pac J Soc Work Dev 2018;28:128-40.

3 Song Y, Anderson RA, Corazzini KN, et al. Staff characteristics and care in Chinese nursing homes: a systematic literature review. Int $J$ Nurs Sci 2014;1:423-36.

4 Chan YK, Lee RPL, Size N. Network size, social support and happiness in later life: a comparative study of Beijing and Hong Kong. J Happiness Stud 2006;7:87-112.

5 Wong YC, Leung J. Long-Term care in China: issues and prospects. J Gerontol Soc Work 2012;55:570-86.

6 Zhan HJ. Population aging and long-term care in China. Generations 2013;37:53-8.

7 Hao Q, Wu S, Ying L, et al. Current dilemmas of nursing homes in Chengdu: a cross-sectional survey. J Am Med Dir Assoc 2012;13:406.e9-406.e12.

8 Feng Z, Liu C, Guan X, et al. China's Rapidly Aging Population Creates Policy Challenges In Shaping A Viable Long-Term Care System. Health Aff 2012;31:2764-73.

9 Zhang $\mathrm{H}$. Who will care for our parents? changing boundaries of family and public roles in providing care for the aged in urban China. Care Manag J 2007;8:39-46.

10 Lee ACK, Wong AKP, Loh EKY. Score in the Palmore's Aging Quiz, knowledge of community resources and working preferences of undergraduate nursing students toward the elderly in Hong Kong. Nurse Educ Today 2006;26:269-76.

11 Fagerberg I, Ekman S-L. Caring for elderly patients: a longitudinal study of Swedish nursing students' narratives. Health Care in Later Life 1998;3:258-71.

12 Kim O-N, J-w O, Kim Y-S, et al. Impacts of perceived health status and self-efficacy in hospital nurses on their health promoting behaviors. Advances in information Sciences and Service Sciences 2014;6:139-44.
13 Bandura A. Perceived self-efficacy in cognitive development and functioning. Educ Psychol 1993;28:117-48.

14 Gibbons C. Stress, coping and burn-out in nursing students. Int $J$ Nurs Stud 2010;47:1299-309.

15 Hweidi IM, Al-Hassan MA. Jordanian nurses' attitudes toward older patients in acute care settings. Int Nurs Rev 2005;52:225-32.

16 Gallagher S, Bennett KM, Halford JCG. A comparison of acute and long-term health-care personnel's attitudes towards older adults. Int J Nurs Pract 2006;12:273-9.

17 Jacelon CS. Attitudes and behaviors of hospital staff toward elders in an acute care setting. Appl Nurs Res 2002;15:227-34.

18 Yenișehir S, Çıtak Karakaya İlkim, Karakaya MG. Knowledge and practice of nursing home caregivers about urinary incontinence. Eur Geriatr Med 2019;10:99-105.

19 Cyprus Network. The growth rate of the elderly population in Liaoning Province slowed down in 2017, and the population of young and old people increased rapidly, 2017. Available: https://sh.qihoo. com/9715f9adce7664579? cota $=1$ \&refer_scene $=$ so_1\&sign $=360$ e39369d1

20 Peduzzi P, Concato J, Feinstein AR, et al. Importance of events per independent variable in proportional hazards regression analysis. II. accuracy and precision of regression estimates. J Clin Epidemiol 1995;48:1503-10.

21 Peduzzi P, Concato J, Kemper E, et al. A simulation study of the number of events per variable in logistic regression analysis. $J$ Clin Epidemiol 1996;49:1373-9.

22 Palmore E. Facts on aging: a short quiz. Gerontologist 1977;17:315-20.

23 Kane RL. Ageism: negative and positive 2nd edition. Journal of Public Health Policy 2000;21:247-9.

24 Wang C-C, Liao W-C, Kuo P-C, et al. The Chinese version of the facts on aging quiz scale: reliability and validity assessment. Int $J$ Nurs Stud 2010;47:742-52.

25 Kogan N. Attitudes toward old people: the development of a scale and an examination of correlates. J Abnorm Soc Psychol 1961;62:44-54.

26 Wang CC, Liao WC, Kao MC, et al. Taiwanese medical and nursing student interest levels in and attitudes towards geriatrics. Ann Acad Med Singapore 2009;38:230-6.

27 Yen C-H, Liao W-C, Chen Y-R, et al. A Chinese version of Kogan's attitude toward older people scale: reliability and validity assessment. Int J Nurs Stud 2009;46:38-44.

28 Zhang JX, Schwarzer R. Measuring optimistic self-beliefs: a Chinese adaptation of the general self-efficacy scale. PSYCHOLOGIA 1995;38:174-81.

29 Schwarzer R, Bäßler J, Kwiatek P, et al. The assessment of optimistic Self-beliefs: comparison of the German, Spanish, and Chinese versions of the general self-efficacy scale. Appl Psychol 1997; 46:69-88.

30 Fang LC. Informal employment and gender implications in China: the nature of work and employment relations in the community services sector. Int J Hum Resour Man 2006;17:1471-87.

31 Doherty M, Mitchell EA, O'Neill S. Attitudes of healthcare workers towards older people in a rural population: a survey using the Kogan scale. Nurs Res Pract 2011;2011:1-7.

$32 \mathrm{Hu} \mathrm{SH}$, Yu Y-M, Chang W-Y, et al. Social support and factors associated with self-efficacy among acute-care nurse practitioners. $J$ Clin Nurs 2018;27:876-82.

33 Lambrinou E, Sourtzi P, Kalokerinou A, et al. Attitudes and knowledge of the Greek nursing students towards older people. Nurse Educ Today 2009;29:617-22.

34 Benesty J, Chen J, Huang Y, et al. Pearson Correlation Coefficient. In: Cohen I, Huang Y, Chen J, et al, eds. Noise reduction in speech processing. Berlin, Heidelberg: Springer Berlin Heidelberg, 2009: 1-4.

35 Tierney AJ, Lewis SJ, Vallis J. Nurses' knowledge and attitudes towards older patients admitted to acute orthopaedic wards. $J$ Orthop Nurs 1998;2:67-75.

36 Gaugler JE, Mittelman MS, Hepburn K, et al. Predictors of change in caregiver burden and depressive symptoms following nursing home admission. Psychol Aging 2009;24:385-96.

37 Scerri A, Scerri C. Nursing students' knowledge and attitudes towards dementia - a questionnaire survey. Nurse Educ Today 2013;33:962-8.

38 Humphris GM, Turner A. Job satisfaction and attitudes of nursing staff on a unit for the elderly severely mentally infirm, with change of location. J Adv Nurs 1989;14:298-306.

39 Sung K-taik. Respect for elders: myths and realities in East Asia. Journal of Aging Identity 2000;5:197-205.

40 Zhou X, Zhang J, Song X. Gender discrimination in hiring: evidence from 19,130 resumes in China. SSRN J 2013. 
41 Shaffer MA, Joplin JRW, Bell MP, et al. Gender discrimination and Job-Related outcomes: a cross-cultural comparison of working women in the United States and China. $J$ Vocat Behav 2000;57:395-427.

42 Lamb HR. Staff burnout in work with long-term patients. Psychiatric Services 1979;30:396-8.

43 S P. Interactions of nurses with elderly patients: relationship to nurses' attitudes and to formal activity periods. J Adv Nurs 2010;18:14-19.

44 Zuo H. Formal and informal employment in China: probability of employment and determinants of monthly wages. Aust Econ Rev 2013;46:405-23.

45 Idrees Z, Xinping X, Shafi K, et al. Effect of salary, training and motivation on job performance of employees. American Journal of Business, Economics and Management 2015;3:55-8.

46 Apha Meeting and Exposition. Undergraduate nursing students and the elderly: an assessment of attitudes in a Turkish university, 2017.
47 Monnot MJ, Beehr TA. Subjective well-being at work: disentangling source effects of stress and support on enthusiasm, contentment, and meaningfulness. J Vocat Behav 2014;85:204-18.

$48 \mathrm{Li} \mathrm{J}$, He Z, Luo Y, et al. Perceived transcultural self-efficacy of nurses in general hospitals in Guangzhou, China. Nurs Res 2016;65:371-9.

49 Hendrix CC, Landerman R, Abernethy AP. Effects of an individualized caregiver training intervention on self-efficacy of cancer caregivers. West J Nurs Res 2013;35:590-610.

50 Uysal A, Albayrak B, Koçulu B, et al. Attitudes of nursing students toward people with disabilities. Nurse Educ Today 2014;34:878-84.

51 Howell D, Butler L, Vincent L, et al. Influencing nurses' knowledge, attitudes, and practice in cancer pain management. Cancer Nurs 2000;23:55-63.

52 Pan H-H, Shih H-L, Wu L-F, et al. Path modeling of knowledge, attitude and practice toward palliative care consultation service among Taiwanese nursing staff: a cross-sectional study. BMC Palliat Care 2017;16:42 